\title{
Conceptualizing Information Technology Governance Model for Higher Education: An Absorptive Capacity Approach
}

\author{
Binyamin Adeniyi Ajayi ${ }^{1}$, Husnayati Hussin ${ }^{2} *$ \\ ${ }^{1}$ Ministry of Economic Planning and Budget, Lagos, Nigeria \\ ${ }^{2}$ Faculty of ICT, International Islamic University Malaysia, Malaysia
}

\begin{tabular}{l} 
Article Info \\
\hline Article history: \\
Received Nov 27, 2017 \\
Revised Dec 28, 2017 \\
Accepted Jan 11, 2018 \\
\hline
\end{tabular}

Keywords:

Absorptive capacity

Conceptual model

Higher education

IT governance

Organizational learning

\begin{abstract}
Information Technology (IT) governance has been emerging as a central issue in many organizations. This is because IT governance is key to realizing IT business value. Past studies have focused on the three aspects of IT governance, namely, structural capability, process capability and relational capability. At the same time, some studies have suggested that IT governance process should be viewed as a learning process rather than a problem solving process. Based on this scenario, the role of knowledge and knowledge based processes should be the central focus of IT governance. As a learning process, IT governance effectiveness can be determined by how much impact IT governance practices has influenced on decision-makers' thinking and actions. In this case, knowledge capacity absorbed from IT governance experience reflects a certain level of organizational learning (OL) achieved which later influences the level of IT governance performance. Since studies that adopt this perspective is lacking, this paper proposes a conceptual framework based on absorptive capacity approach for an IT governance performance model in the higher education. The paper contributes theoretically by extending the knowledge of IT governance by exploring a new perspective on OL.
\end{abstract}

Copyright $\odot 2018$ Institute of Advanced Engineering and Science. All rights reserved.

\section{Corresponding Author:}

Husnayati Hussin,

Faculty of Information and Communication Technology,

International Islamic University Malaysia,

P.O.Box 10, Kuala Lumpur, Malaysia.

Email: husnayati@iium.edu.my

\section{INTRODUCTION}

Information Technology (IT) governance has emerged as an important issue for organizations around the world. The advancement in technology has led to more organizations increasing their use of IT and hence increasing their IT investments [1]. This critical dependence on IT demands good governance on IT resources to ensure value is generated from the IT investment.

However, implementing IT governance can be an extremely a complex undertaking. IT governance is said to be concerned with IT project selection and prioritization and authority for resources and the responsibility for IT are shared between IT and business partners [2]. To implement IT governance effectively, a set of IT governance mechanism is required to ensure congruence with the organizational missions and goals, which in turn promotes desirable IT behaviour and governance outcome [3]. Such effective IT governance implies the capability to align IT and organisational goals in a symbiotic way.

While there has been several studies in the past that examined the link between IT governance effectiveness and organizational performance, the findings are still not conclusive. According to [4], the detail on how exactly IT governance affect organizational performance is yet to be understood. In other words, which precise mechanisms IT governance exerts its effect on performance is still unclear. Hence, this study attempts to fill this gap by exploring this link from the organizational learning (OL) perspective. 
Specifically, the purpose of this paper is to develop an IT governance evaluation model using the Absorptive Capacity approach, which is part of the OL theory. The model is developed for the context of higher education, as a review of part literature indicate that most IT governance models were developed for private organizations and very few considered the higher education sector. Moreover, higher educational institutions (HEIs) are in the midst of transformation and becoming more dependent on IT to achieve their organizational missions and goals. Hence, IT governance is considered as a critical issue in HEIs just like the profit-oriented counterparts.

\section{REVIEW OF RELATED LITERATURE}

\subsection{Defining IT governance}

There is still no consensus on how to define IT governance [5]. This may be due to the different perspectives researchers have taken into consideration when making such definitions. According to [6], the IT Governance Institute (ITGI) and Weill and Ross's definitions are the most adopted among Information Systems researchers. The ITGI defines IT governance as the leadership, organizational structures and processes that ensure that the organization's IT sustains and extend the organizations missions and objectives [7]. Weill [3] defined IT governance as specifying the decision rights and accountability standard to encourage desirable IT behaviour. Based on the above definitions and a synthesis of other definitions as well [8]-[10], this paper considers IT governance as "IT behaviour deliberately designed and adopted by an enterprise to enable continuous organisational performance".

IT governance implementation is influenced by external and internal factors. Several past studies have examined the factors that affect IT governance implementation [11]. Some of the factors identified include organizational culture and structure, strategy, size, regional differences, industry, maturity, ethics and trust [5]. Past researchers agreed that when IT and business appreciates their capabilities and are aligned, the goal of investment in IT is achievable. Such relationship can only be achieved when there is a deliberate crafting and design of governance by the leadership which is cascaded down the enterprise to enable desirable IT behaviour.

Recently, researchers have started to identify key governance mechanisms contributing to effective IT governance. For example, [12] investigated the influence of IT governance mechanisms on IT governance effectiveness in the Australia public sector. The study found two factors namely, the existence of an IT strategy committee and corporate communication systems, to be significant predictors for effective IT governance.

\subsection{IT Governance and Organization Performance}

The impact of IT governance on organizational performance has been well established in several past studies. For example, [3] found that top-performing companies generate up to $40 \%$ higher return on IT investment than their competitors because of companies can get more value from IT through more effective IT governance. Effective IT governance is critical since most organizations invest heavily in IT and also because IT governance enable organizations to explore new business opportunities.

Such ITG practices influence IT and business alignment of the organisation as the enterprise is well aware of the direction of IT [13]. The result of such awareness is higher governance performance. This is because senior managers are able to describe the ITG given their ability to explore their knowledge and thus be able to leverage IT [2].

\subsection{IT Governance in Higher Education}

HEI, do harness IT in transforming education, learning and development. As a result, the use of IT is on the increase especially with the demand for globalisation and liberalisation which make HEIs need to become flexible in service delivery. In fact, the demand for IT based products has increased due to increase in students' population [14]. With the increasing use of IT among HEIs, so the critical need for its effective governance.

For HEIs, IT governance means ensuring that the university IT strategy is aligned with the institution's strategic plan [15]. The 2013 EDUCAUSE Centre for Applied Research (ECAR) report highlighted that only 10 percent of the responding institutions have very effective IT governance program; 61 percent have somewhat effective or ineffective IT governance programs [15]. While IT governance seemed to be a critical issue in HEIs, very few studies have been done to examine the issue this context.

[16] investigated the issues related to IT governance in a public university in Malaysia using a case study method and found that the university lacks a common approach in decisions related to IT planning, IT funding and IT project development. [17] studied eight Australia universities and found that decentralized structure is the most common and these universities are at different levels of maturity in terms of IT 
governance practices. A study on HEI in Thailand by [18] found IT governance at Thai universities were in the initial stage and most IT executives were not familiar with IT principles.

More recently, [19] examined the role of IT executives in higher education by looking at the skills and experience necessary to be a Chief Information Officer (CIO). Using a qualitative study, the findings indicated that an effective CIO for HEI need to have multi-dimensional personalities, diverse experience and must have higher education background.

While the above studies look at IT governance in the context of HEIs, the specific on how HEIs management evaluate performance with respect to governance of IT is relatively scarce in the literature.

\section{THEORETICAL DEVELOPMENT}

\subsection{Organizational Learning Theory}

Organizational learning theory is concerned with development of insights, knowledge and associations between past actions, the effectiveness of those actions and future actions. Organisations are assembly of functions learning in an atmosphere that comprises largely of learning sub-units. Learning has been defined as a process by which organisations develop competence through use and among which they choose based on experience. This ability of an organisation is a function of the capacity of the individual in its community to recognise and acquire needed information. Learning thus depends largely on the features of the memories of its constituent members [20] in their ability not only through the discovery of new knowledge but the ability to create new ones.

Past researches on organizational learning focused on two streams: exploration and exploitation. Exploration refers to learning gained through processes of concerted variation, organizational experimentation and quests for knowledge for unknown market opportunities. Exploitation refers to learning gained via local search, experiential refinement and the use of existing knowledge, competencies, and technologies [21], [22] relate absorptive capacity processes to three learning processes: Exploratory learning is used to recognize and understand new external knowledge, transformative learning combines new knowledge with existing knowledge thereby enable organization to assimilate valuable external knowledge, and exploitative learning is used to apply the assimilated external knowledge. In short, absorptive capacity and organizational learning are definitely related but how they are related is still not clear. While absorptive capacity is a well-defined construct, OL is broad concept and considered as a theory. While absorptive capacity focuses on the role of external knowledge, OL spans both internal and external knowledge. While it is implied that organizations should actively increase their absorptive capacity, organizations can learn either actively or passively.

\subsection{Absorptive Capacity}

Absorptive capacity is defined as the ability to identify, assimilate, transform and apply external knowledge [20]. Absorptive capacity is a construct of organisation learning (OL) which is contingent upon an organisation's ability to, through its related prior knowledge, explore new knowledge, assimilate or transform it and apply it to commercial ends and for the value creation [20]. Absorptive capacity is a multi-dimensional construct that consists of three distinct yet interrelated capabilities: knowledge identification, knowledge assimilation/transformation, and knowledge application [22]. An organization's ability to absorb valuable external knowledge depends on its level of prior knowledge. When viewed as an asset, absorptive capacity is conceptualized as the level of relevant prior knowledge possessed by the organization. However, absorptive may be viewed as substantive organizational capability which viewed routines and processes as ways to identify, assimilate/transform and apply external knowledge, or as dynamic capability which refers to capacity of an organization to purposefully create, extend, or modify its resources base. [21] mentioned that the predominant view is that absorptive capacity is an organizational capability, not an asset.

Looking through past literature, [21] found that IS researchers both conceptualize and operationalize absorptive capacity as either an asset or a capability. For example, absorptive capacity is measured as a leadership's ability to recognize valuable business and IT information, develop learning, and apply learning in guiding organizational IT innovation activities. An organization's absorptive capacity is derived in part through the character and distribution of expertise within the organization. One of the specialized knowledge base of an organization is business-IT knowledge. This refers to the combination of IT-related and businessrelated knowledge possessed by and exchanged among IT and business managers.

Based on available definition of Absorptive Capacity by [20], [22] and the fact that IT have important roles in the realisation of organisational objectives, governance of IT is necessary which will lead to developing IT capabilities that is leveraged upon to enable organisational learning. Thus it is suggestive that for organisation continuous leverage of IT there is need to focus on IT absorptive capacity. Thus this is the capacity to purposefully create, extend or modify the organisation knowledge-base through some set of 
routines and processes. Such ability is not just to identify new business-IT knowledge but also to be able to assimilate the new knowledge or transform the existing one to accommodate new knowledge and apply it for creating business value.

This paper see the IT governance absorptive capacity as a function of the effectiveness of the organisation's IT governance which necessarily implies that IT and business understand and appreciates each other and are thus aligned. The fact is that when organisation focus more on implementing sound IT governance strategies based on collaboration and experience sharing, senior executive managers are assisted to appreciate the perceptions between IT and enterprise. The result in such case will be an organisation with a better performance.

\subsection{The Proposed Research Model}

The proposed research model is shown in Figure 1.

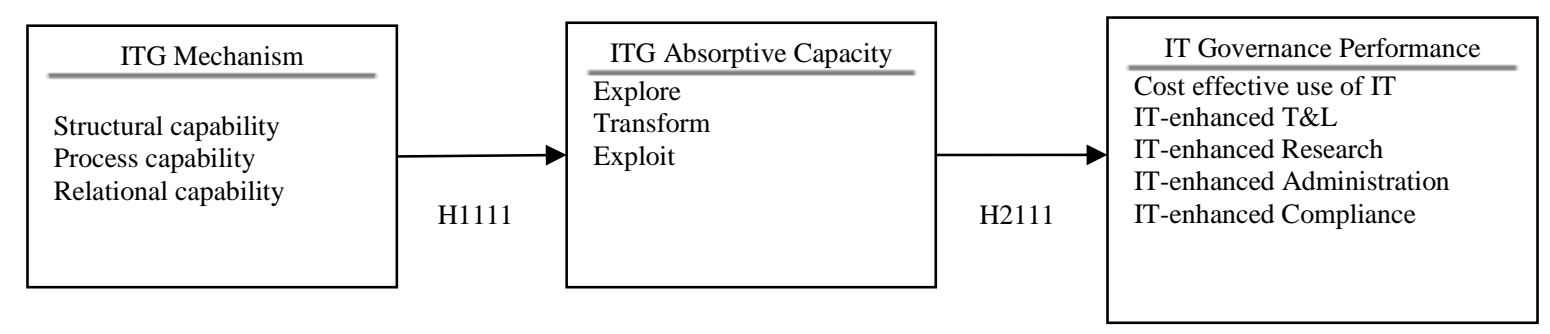

Figure 1. IT governance-absorptive capacity model for HEI

The overall rational for the model is that the implementation of IT governance mechanisms can facilitate the HEI's ability to absorb valuable external knowledge which thereby leads to higher organizational performance. Although there have been past studies that have examined and validated the link between IT governance and organizational performance (for example, [3]), none have examined the impact of IT mechanisms on organizational performance from the lens of absorptive capacity. In other words, it is not well understood how the organizations capitalize on their prior knowledge of IT governance and integrate it with relevant external knowledge and apply this new knowledge of IT governance to affect the performance of the organization. This model is proposed to gain insights on the impact of IT governance on HEI

The dependent variable is the HEI performance impacted by the level of IT governance absorptive capacity, which in turn was affected by the level of IT mechanism capability. IT governance absorptive capacity mediates the impact of IT governance on organizational performance. The following section will discuss the variables and hypotheses of the model in detail.

\section{OPERATIONALIZATION OF VARIABLES AND HYPOTHESES DEVELOPMENT}

This section will discuss on each of the variables in the research model and followed with justification for hypotheses development.

\subsection{IT Governance Mechanism}

[9] proposed that IT governance can be implemented through a framework of structures, processes and relational mechanisms. Similarly, [3] proposed that effective IT governance employ three different types of mechanisms, namely, decision-making structures, alignment processes and communication approaches. They argued that having these three mechanisms in place will promote desirable IT behaviour which in turn lead to desired performance goals.

IT structural capability concern with the capability of an organisation in designating positions, roles and responsibilities on IT. Structures involve clearly defined roles and responsibilities and a set of IT/Business committees such as steering committee. Earlier studies on IT governance have focused on this aspect of IT governance where the concern was how IT was structured in an organisation. However, knowledge of this aspect has evolved over the years and today many realized that there is no single pattern can be considered as the best. [3] came up with a broader view of IT structure, arguing that no pattern of IT structure is the best for all organizations. Researchers have operationalised IT structural capability in various ways including IT strategy committee, IT steering committee, CIO on Board, Architecture Steering 
Committee, CIO reporting to the CEO or COO, IT Expertise at the level of the board of Directors and Business/IT Relationship Managers [1], [13].

IT process capability refers to IT governance processes and competencies associated with successful implementation and use of IT. It covers procedures involved in arriving at strategic IT decision-making as well as its monitoring [8], [13] to achieve the desired IT behaviour. [14] posit that this consist of various IT governance frameworks or tools to examine IS activities and value to business. Ribbers, Peterson and Parker (2002) argues the fact that both management tools, in form of frameworks, and experiences of the way they are implemented, are very important contingencies of IT governance outcome. This mechanism includes IT Balanced Scorecard, Service Level Agreement, Portfolio Management, Chargeback, ITG Framework CobiT, project governance/management technologies, strategic information systems planning [1].

Relational capability refers to the strategic dialogue, shared learning and participation between business and IT and among stakeholders within the enterprise. This aspect of the IT governance mechanism is regarded as very important in the attainment of business and IT alignment [13]. This is where the bulk of knowledge acquired via interaction of business and IT side of the organisation may be exploited to the benefit of the consumer. The importance of business and IT is pronounced when the concern is on understanding how policies and decisions or how processes for using IT effectively in an organisation are arrived at. The higher the ability of senior management to describe the IT governance of an organisation, the higher the governance performance as it is an indication of effective governance [2], [3]. This mechanism include IT leadership, IT governance awareness campaigns, informal meetings between business and IT executive, job rotation, business/IT account management [1].

Past researchers who have investigated the impacts of specific IT governance mechanism on the overall effectiveness of IT governance include [13] and [12]. Their findings indicated some positive influence of IT governance mechanism on IT governance effectiveness. [4] highlighted that a more complete and solid empirical support for the three types of governance mechanisms identified is still insufficient. Additionally, the specific influence of each type of IT governance capabilities has not been explored in the context of higher education. Hence this study attempt to contribute to the knowledge domain by understanding how IT governance mechanism affect IT governance effectiveness based on absorptive capacity approach. Hence the following hypothesis is derived:

H1: IT governance mechanism positively influence IT governance absorptive capacity in HEIs.

\subsection{IT Governance Absorptive Capacity}

Exploring the level of business and IT knowledge in an organisation that leverage IT provide another way of looking at how this impact on the performance. Business-IT knowledge is seen here as the relationship between both internal within the organisation and external with extra-ministerial organisations that has to be dealt with in the business of the organisation. [21] sees this knowledge as a combination of ITrelated and business-related knowledge possessed and exchange by business and IT managers. At the individual level it involves the competency possessed by either the business manager or its IT counterpart. At the collective level it refers to shared domain knowledge between the business and IT managers [21]. This implies the ability of the business manager to understand IT capability and its IT counterpart understanding ways through which IT can be deployed to beget organisational efficiency and effectiveness.

IT governance absorptive capacity is dimensioned as the business-IT knowledge which involves the capability to identify and create valuable knowledge; assimilate the knowledge and apply the knowledge to enable organisation performance [21], [22]. Thus we proposed that effective IT governance absorptive capacity is a multi-dimensional construct of business-IT knowledge which will be measured on the level of knowledge acquisition, knowledge assimilation and knowledge exploitation. In the context of higher education, knowledge acquisition refers to the extent the institutional players recognize the value of external knowledge and acquire them for the benefit of achieving the HEI goals. For example, to what extent the academicians recognize the value of learning about technology-support teaching and learning, and eventually apply it to their own classrooms. To gain the real impact of technology-based education, HEI have to ensure assimilation of this new knowledge among majority of their academics. To sustain competitive advantage over other institutions, the HEI need to exploit this approach and this require not just mere utilization of the technology but include innovative use and strategic thinking in the implementation of the technology.

The seminary works of [3] points to the fact that organisations that effectively governed their IT gained $20 \%$ higher in profit than others with poor IT governance when they pursued similar strategies. Other studies that found similar findings include [11], [6], [24]. Although HEIs are non-profit organizations, it is postulated that similar impacts of IT governance effectiveness on IT governance performance will be achieved. Hence, this hypothesis is proposed:

H2: IT governance absorptive capacity positively influence IT governance performance in HEIs. 


\subsection{HEI IT Governance Performance}

Measuring performance is an endeavour in the right direction as IT contributes a lot to the wellbeing of organisation [14]. Such measure is important because large portion of investments in IT does not guarantee high returns if not properly governed. Performance of an organisation is hinged on its ability to align structure to the factors relative to the organisation. Organisational style that is strategically effective in one HEI may not necessarily be in others, despite the fact that they may be operating within the same sector [13]. Since the focus is on HEIs which are not all for-profit, but mission-oriented organisations, performance is considered from the perspective of how HEIs measures benefits gained from their IT investments which is enabled by its effective governance.

For this study, organizational performance is operationalized by adapting four out five taxonomies of [3] and an additional measure on compliance is adapted from [23]. The suggested measures are as follows:

- Cost effective use of IT

- Effective use of IT to enhance teaching and learning

- $\quad$ Effective use of IT to enhance research

- Effective use of IT to enhance HEI administrative processes

- Effective use of IT to enhance compliance with legal and regulatory requirements

\subsection{IT Governance Absorptive Capacity as Mediator}

The achievement of HEI goals can be achieved through IT by implementing an effective IT governance framework. IT governance mechanisms serve as an institutional arrangements that allow CIOs and HEI executives to better contribute their domain knowledge, interact with each other to share perspective and transfer knowledge between the two groups. For example, the allocation of decision rights to the IT unit allows IT managers to use more of their IT knowledge to help Deans/Directors of the HEIs to identify effective IT solutions for their faculties which they may not be able to identify themselves. IT governance absorptive capacity is one of the mediating factors considered to be important and necessary conditions in the chain of value creation. Taken together, we posit that:

H3: IT governance absorptive capacity mediates the positive impact of IT governance mechanisms on IT governance performance in HEIs.

\section{CONCLUSIONS}

The importance of IT governance is evident through the attention it receives from scholars and practitioners. As noted previously, past IT governance researches have focused on business organizations and very few examined it in the public sector context. Higher education is one of the sectors that have been most affected by IT use and therefore the top management of these institutions are very concern with the value received from IT investment, hence the importance of IT governance. Unfortunately, not much has been studied on IT governance in the context of HEIs, particularly looking at the link between IT governance and HEI performance. This paper attempt to fill the gap by proposing an IT governance evaluation model based on the perspective of organizational learning.

IT governance mechanisms of an organisation consist of the structural, process and relational capabilities which are contingent factors upon which the IT function can leverage appropriate and continuous business and IT knowledge. Such knowledge is borne out of the inter-relationship of both the IT and business functions within the organisation. The capability of the organisation IT to leverage on this interaction given these factors is a function of its dynamic capability to explore by identifying and creating knowledge. Such ability will be through the IT structural capability put in place. The IT organisation is expected to effective transform such knowledge putting the technology process capability into action. This continuous interaction will allow the IT function, through the cordial relationship, to apply knowledge that have so far being acquired or created for organisation performance.

Organisation performance could be continuously measured by looking into how IT is governed. How IT is used to optimise cost, to leverage growth, to achieve optimal use of asset and the ability for it to be flexible to business need should be the benchmark in any organisation as at that. Lastly, the way the organisation is using IT to comply with regulations of corporate governance like IT auditing, risk management etc. is also important aspect that makes investment in IT yield a worthwhile venture. This is when the stakeholders would be ever willing to invest and accord the IT the place it deserves in the organisation.

In conclusion, it can be assumed that when organisation's IT governance is effective, desirable IT behaviour is said to be present. This is to say that when organisation exercises desirable IT behaviour in the design of governance mechanisms of structures, processes and relationship in IT as influenced by corporate 
existence, then IT and business is aligned. Such a situation depicts that IT understands the business needs and can sustain business objectives, giving the business-IT knowledge that would ensue. At the same time the business is also acquainted with the capabilities of IT that would enable organisation performance.

\section{REFERENCES}

[1] Almeida, R., Pereira, R., \& Mira, M. (2013). "IT Governance Mechanisms : A Literature Review". In J. F. e Cunha, M. Snene, \& H. Nóvoa (Eds.), Proceedings, 4th International Conference, Exploring Services Sence (IESS 2013) (pp. 186-199). Porto, Portugal: Springer Berlin Heidelberg.

[2] Weill, P. (2004). "Don’t Just Lead, Govern: How Top-Performing Firms Govern IT". MIS Quarterly Executive, 3(1), $1-17$.

[3] Weill, P., \& Ross, J. W. (2004). IT Governance How Top Performers Manage IT Decision Rights for Superior Results (p. 265). Boston, MA: Harvard Business School Publishing.

[4] $\mathrm{Wu}$ et al, (2015)."How Information Technology Governance Mechanisms and Strategic Alignment Influence Organizational Performance: Insights from A Matched Survey of Business and IT Managers", MIS Quarterly, Vol.39, No.2, pp. 497-518.

[5] Pereira R. and Mirada Silva, M. (2012) "A Literature Review: Guidelines and Contingency Factors for IT Governance", Proceedings of the European, Mediterranean \& Middle Eastern Conference on Information Systems 2012, June 7-8, Munich, Germany.

[6] Nfuka, E. N., \& Rusu, L. (2011). "The effect of critical success factors on IT governance performance". Industrial Management \& Data Systems, 111(9), 1418-1448.

[7] ITGI, (2003). Board Briefing on IT Governance, Rolling Meadows, IL 60008 USA: ITGI.

[8] Peterson, R. R. (2004). "Crafting Information Technology Governance". Information Systems Management, 21(4), $7-22$.

[9] De Haes, S., \& Van Grembergen, W. (2004). "IT Governance and Its Mechanisms". Information Systems Control Journal, 1, 1-7.

[10] Webb, P., Pollard, C., \& Ridley, G. (2006). "Attempting to Define IT Governance: Wisdom or Folly?" In Proceedings of the 39th Hawaii International Conference on System Sciences (Vol. 00, pp. 1-10). IEEE.

[11] Mohamed, N., \& Kaur, J. (2012). "A conceptual framework for information technology governance effectiveness in private organizations A conceptual framework for information technology governance effectiveness in private organization". Information Management \& Computer Security, 20(2), 88-106.

[12] Ali, S., Green, P. and Robb, A. (2012) "Measuring Top Management's IT Governance Knowledge Absorptive Capacity, Journal of Information Systems, Vol.27, No. 1, pp. 137-155.

[13] Van Grembergen, W., \& De Haes, S. (2009). Enterprise Governance of IT in Practice. Boston, MA: Springer US.

[14] Bhattacharjya, J., \& Chang, V. (2007). "The Role of IT Governance in the Evolution of Organizations in the Digital Economy: Cases in Australian Higher Education". In 2007 Inaugural IEEE International Conference on Digital Ecosystems and Technologies (IEEE DEST 2007) (pp. 428-433).

[15] Grama and Peterson, (2013) "Governance, Risks and Compliance: Why Not?", EDUCAUSE Review, Nov/Dec 2013.pp. 11-13.

[16] Ismail, N. A. (2008). "Information technology governance, funding and structure: A case analysis of a public university in Malaysia". Campus-Wide Information Systems, 25(3), 145-160

[17] Hicks, M., Pervan, G. \& Perrin, B. (2012) "A Study of the review and improvement of IT governance in Australian universities", CONF-IRM 2012 Proceedings. Paper 22.

[18] Jairak, K. \& Praneetpolgrang, P. (2011) "A Holistic Survey of IT Governance in Thai Universities through IT Executives Perspective", In: A. Abd Manaf et al (Eds.): ICIEIS 2011, :Part II, CCIS 252, pp. 435-447.

[19] Dlamini R.S. (2015) "The Role of the Strategic and Adaptive Chief Information Officer in higher education", Educational Information Technology, Issue 20, pp. 113-140.

[20] Cohen, W. M., \& Levinthal, D. A. (1990). "Absorptive Capacity: A New Perspective on Learning and Innovation". Administrative Science Quarterly, 35(1), 128-152.

[21] Roberts, N., Galluch, P. S., Dinger, M., \& Grover, V. (2012)." Absorptive Capacity and Information Systems Research: Review, Synthesis, and Directions". MIS Quarterly, 36(2), 625-648.

[22] Lane, P. J., Koka, B. R., \& Pathak, S. (2006). "The Reification of Absorptive Capacity: a Critical Review and Rejuvenation of the Construct". Academy of Management Review, 31(4), 833-863

[23] Bowen, P. L., Cheung, M.-Y. D., \& Rohde, F. H. (2007). "Enhancing IT governance practices: A model and case study of an organization's efforts". International Journal of Accounting Information Systems, 8(3), 191-221.

[24] Simonsson, M., Johnson, P., \& Ekstedt, M. (2010). "The Effect of IT Governance Maturity on IT Governance Performance". Information Systems Management, 27(1), 10-24. 


\section{BIOGRAPHIES OF AUTHORS}

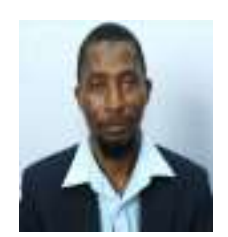

Binyamin Adeniyi Ajayi, PhD, is currently a Director at the Lagos Bureau of Statistics Ministry of Economic Planning \& Budget, Lagos, Nigeria. He received his PhD in IT from the Faculty of Information \& Communications Technology at the International Islamic University Malaysia. His research interest include IT governance and Ethics.

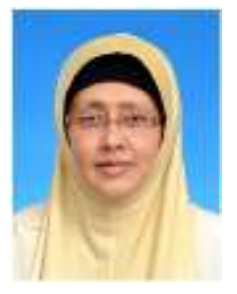

Husnayati Hussin, PhD is a Professor of Information Systems in the Faculty of Information and Communications Technology at the International Islamic University Malaysia. She received her $\mathrm{PhD}$ in Information Systems from the Loughborough University, UK and her MSc in Management Information Systems and BSc in Computer Science from Northern Illinois University, USA. Her current research interest include E-business, IT management, IT and small business, E-Government and ethical issues of IT. She has published articles in journals such as Journal of Strategic Information Systems, International Journal of Electronic Government Research, Campus-Wide Information Systems, Total Quality Management and Business Excellence and Business Process Management Journal. 